\title{
CHEMICAL COMPOSITION VERSUS ELECTRICAL CONDUCTIVITY
}

\author{
BY COLIN G. FINK
}

Some years ago, while still at the University, I carried out a number of experiments on the electrothermic production of ultramarine; powdered mixtures of sodium sulphide, china clay and carbon were interposed between carbon electrodes in a closed crucible furnace. I observed at that time that in order to keep the electrical resistance and the temperature of the charge fairly low so as to avoid decomposition of the ultramarine as soon as it was formed, it was necessary to use very finely divided carbon, such as lampblack. With charges made up of powdered coke which was coarse compared to the lampblack, I could not get any appreciable current to pass between the carbon electrodes up to potentials of $25^{\circ}$ volts. Subsequently, I have found repeatedly that the electrical conductivity of mixtures of finely divided substances is a function of the relative size of the components.

\section{Experimental}

A series of tests was made in order to get values of a more quantitative nature. Two substances were selected, the physical properties of the one as divergent as possible from those of the other: a black metal powder, tungsten, and a white insulator powder, thoria. The advantages in this selection are manifold. Both tungsten and thoria will stand very high temperatures and can, therefore, be made practically moisture-proof. It is a well-known fact that in all high resistance tests adsorbed moisture is a very disturbing factor. As regards metals such as copper and silver, these were not serviceable since they cannot be heated to high temperatures without partial vaporization, which though slight is sufficient to cover the surface of the insulator granules with a highly conductive film. Other factors that decided our selection in favor of tungsten and thoria were: (I) High state of purity; (2) availability of both in extremely fine powdered form 
(readily sifted through 250 mesh silk gauze); (3) constancy and stability under ordinary atmospheric conditions; (4) sharp distinction in color; (5), high specific gravities (which reduced the tendency to dust).

All mixtures here recorded were made up of equal weights of tungsten and thoria. As regards the size of the particles, the mixtures would pass readily through silk having 250 meshes to the inch. The holes in this silk are about $0.025 \mathrm{~mm}$ (0.00 I") in diameter. Attempts to segregate particles of a welldefined size by such methods as suspending in water, or in organic liquids or in air, were frustrated on account of the persistent tendency of the very fine particles to form agglomerates.

We finally resorted to the familiar "tap test," which gave us fairly good comparative values of the fineness of the various powders used. Ten grams of the powder or powder mixtures were filled into a ro cc glass graduate and tapped to constant volume; usually after seven minutes, no further decrease in volume could be detected. The ultimate volume in cc divided by ro gave us the relative volume $\left(v_{p}\right)$ as recorded in Table I. It can easily be demonstrated that the values for $v_{\gamma}$ are a function of the density and mean particle size. At first there seemed to be a serious objection to the tap test, namely this, that a $\mathrm{ThO}_{2}$ or a $\mathrm{W}$ powder composed of, say, equal parts of coarse and fine particles would give the same value for $v_{r}$ as a second powder whose particle size was a mean between the two limiting sizes of the first powder. This objection to the tap test was automatically set aside since, in the ordinary preparation of metal or oxide powders in single small lots, by far the greater majority of particles are very nearly of the same size. This tendency to form a "standard" size is a universal phenomenon, the dimensions of any particular standard being dependent upon physical conditions such as temperature, strength of solution, etc., under which the particular powder is prepared. Compare, in this connection, the uniform size of the crystals of granulated sugar as regulated by the "strike pan." 
TABLE I

\begin{tabular}{c|c|c|c|c|c}
\hline \multirow{2}{*}{ Mixture } & \multicolumn{4}{|c|}{ Relative volume (vr) } & \\
\cline { 2 - 5 } & $\mathrm{ThO}_{2}$ & $\mathrm{~W}$ & $\begin{array}{c}\text { Mixture } \\
\text { Found }\end{array}$ & $\begin{array}{c}\text { Mixture } \\
\text { Calculated }\end{array}$ & $\begin{array}{c}\text { Appearance of } \\
\text { mixture }\end{array}$ \\
\hline $\mathrm{R}$ & 0.720 & $0 . \mathrm{II} 3$ & 0.430 & $0.4 \mathrm{I} 7$ & White \\
$\mathrm{P}$ & 0.720 & 0.350 & 0.565 & 0.535 & White \\
$\mathrm{Z}$ & 0.576 & 0.235 & 0.389 & 0.406 & White \\
$\mathrm{T}$ & 0.305 & $0.1 \mathrm{I} 3$ & 0.200 & 0.209 & White \\
$\mathrm{S}$ & 0.305 & 0.330 & 0.275 & 0.318 & Black \\
$\mathrm{X}$ & 0.238 & 0.577 & 0.420 & 0.408 & Black
\end{tabular}

Referring to Table I, we note that the white thoria powders varied in relative fineness between 0.720 and 0.238 and the black tungsten powders between 0.577 and $0 . I_{1} 3$. In column 5 the calculated value for $v_{r}$ of any mixture is equal to onehalf the stum of the $v_{r}$ values of the $\mathrm{ThO}_{2}$ and $\mathrm{W}$ constituents. These calculated values agree fairly well with the experimental and support our contention that the particles of any freshly prepared powder are of fairly uniform size. If this were not the case no such agreement between the values of columns 4 and 5 would be possible. In the last column of the table is given the appearance of the mixture, whether nearly white or nearly black. If the $v_{r}$ value for the white powder is high as compared with the $v_{r}$ value for the black powder, the appearance of the mixture is white; if the white powder is coarser than the black powder, the appearance of the mixture is black. In other words, whenever the ratio of $v_{p}$ for thoria to $v_{p}$ for tungsten is greater than 2, the mixture is white and if less than 2 the mixture is black, where 2 is equal to the absolute density of tungsten (r9.6) divided by the absolute density of thoria (9.8).

\section{Electrical Measurements}

The powders were pressed into rods $4 \mathrm{~cm}$ long and $1 / 2$ cm square. They were then placed in a tungsten-hydrogen furnace and fired at $1600-160^{\circ}$ for three hours. This firing caused the rods to sinter together, and rendered them practically proof against moisture. The fired rods were kept in a 
$\mathrm{P}_{2} \mathrm{O}_{5}$ desiccator. The rods were then mounted between brass clamps and the resistance measured on a wheatstone bridge with a sensitive galvanometer. Care was taken to make these measurements on days when the humidity of the air was low. ${ }^{1}$

In view of the differences in "color" of the various mixtures in the powdered form, it was not very surprising to find marked differences in the electrical resistances although the firing at $1600^{\circ}$, however, resulted in an almost uniform shade for all of the mixtures. In Table II are recorded four of the characteristic resistance values found: In the last column are the calculated specific resistance values.

TABLE II

\begin{tabular}{c|c|c}
\hline Powder & Resistance & Resistivity \\
\hline $\mathrm{ThO}_{2} \mathrm{No.} \mathrm{2}_{\mathrm{Z}}$ & Over I0 ${ }^{12}$ ohms & Over Io $\mathrm{O}^{12}$ ohms \\
$\mathrm{X}$ & $4 \mathrm{I} .8$ & 173.0 \\
$\mathrm{~W}$ No. I & $0.027 \mathrm{I}$ & 0.108 \\
& 0.0040 & 0.016
\end{tabular}

The powders, $\mathrm{ThO}_{2}$ No. 2 and W No. I, were pressed up into rods the same size as those of the mixtures; they were likewise fired at $1600^{\circ}$ for 3 hours. Since in all of our original powders a small percentage of grains was present whose size was smaller than that of the majority of grains, our results would tend to show that under ideal conditions of mixture, relative grain size and uniform distribution, the resistivity values for white mixtures such as $Z$ would be even higher than here recorded. Similarly, the resistivity values for black mixtures such as $\mathrm{X}$ would be lower than those found, approaching a limiting value equal to twice that of the roo percent metal rod.

\section{Conelusion}

In general we may say that the electrical conductivity of a substance is primarily dependent upon the shape and the

${ }^{1}$ Compare in this connection H. L. Curtis: Phys. Rev., 3, 490 (I9I4), "Surface Leakage over Insulators." 
distribution of the fundamental grains or particles composing the substance, and secondly, upon the presence or absence of thin films of secondary material enveloping these ultimate grains.

On the basis of this theory we can account for the comparatively high conductivity of gels that contain but a trace of conducting material. We can also account for the marked difference in resistance of, for example, two samples of commercial copper whose chemical composition is identical, depending upon whether the impurity, such as sulphur, is uniformly dissolved in the metal or whether it forms a film ("cement") of copper sulphide around pure granules of copper. The latter case is to be regarded, as Bancroft suggested, as an emulsification of copper, in copper sulphide. The high resistance of these surface films composed of, say, sulphide

- or oxide or arsenide accounts for the high resistivity values of copper when but a trace of the impurity is present.

Edison Lamp Works, Harrison, $N . J$. 